\title{
Human papillomavirus prevalence and type-distribution among women in Zhejiang Province, Southeast China: a cross-sectional study
}

\author{
Xiao-Xiang Liu ${ }^{1 \dagger}$, Xing-Li Fan ${ }^{1 \dagger}$, Yue-Ping Yu' ${ }^{1}$, Lei Ji ${ }^{1}$, Jie Yan ${ }^{2,3^{*}}$ and Ai-Hua Sun ${ }^{1^{*}}$
}

\begin{abstract}
Background: Human papillomavirus (HPV) infection is the main etiological factor for cervical cancer and premalignant lesions of the cervix. The purposes of the present study were to determine the prevalence of type-specific HPV infections and the association of different HPV types with cervical dysplasia among women in Zhejiang province, Southeast China.

Methods: A total of 15,267 women presenting to a gynaecological outpatient clinic were enrolled in this study. Women were screened for HPV in addition to routine cervical cytology testing. Microarray hybridization and liquid-based cytology tests were used to detect HPV genotypes and cervical cytology, respectively.

Results: Based on the population attending a gynaecological outpatient clinic, overall prevalence of any 23 HPV type was $22.8 \%$ and multiple HPV infection was found in $4.0 \%$ of all the outpatients. HPV prevalence showed bimodal age distribution, with a peak (55.7\%) at the $\leq 20$ age group and a second one (35.5\%) at $>60$ age group. In total samples, the five most frequent types were HPV 16 (4.4\%), 58 (2.9\%), 52 (2.7\%), 33 (2.2\%) and 11 (1.9\%). Overall HPV prevalence increased with the severity of the cytologic result. Analysis through crude odds ratios (ORs) revealed that the cervical lesion risk of HPV-infected women increased to about 26-fold of uninfected women (OR 26.1, 95\% Cl 22.4 to 30.3). The five most risky HPV types associated with abnormal cytology were HPV 73, 16, 82, 45 and 51.
\end{abstract}

Conclusions: This study provided baseline data on HPV prevalence in women attending a gynecological outpatient clinic in Zhejiang province. Our data will supply guidance for the primary screening and vaccination program for cervical cancer in this area.

Keywords: Human papillomavirus (HPV), Prevalence, Genotyping, Cytology

\section{Background}

Cervical cancer is the second most common cancer among women, with an estimated 530,000 new cases and 275,000 deaths occurring each year in the world [1,2]. There are an estimated $88 \%$ of the annual incidences occurring in developing countries, such as China, where approximately 75,500 new cases and 34,000 deaths occur every year $[2,3]$. According to epidemiological and molecular studies, it is well-established that human

\footnotetext{
*Correspondence: Med_bp@zju.edu.cn; sunah123@126.com

${ }^{\dagger}$ Equal contributors

2Division of Basic Medical Microbiology, State Key Laboratory for Diagnosis and Treatment of Infectious Diseases, First Affiliated Hospital of Zhejiang University, Hangzhou, Zhejiang 310003, P. R. China

${ }^{1}$ Faculty of Basic Medicine, Zhejiang Medical College, Zhejiang, Hangzhou 310053, P. R. China

Full list of author information is available at the end of the article
}

papillomavirus (HPV) infection is the main etiological factor for cervical cancer and premalignant lesions of the cervix $[4,5]$. So far, over 100 different HPV genotypes have been identified, of which nearly 40 types are associated to lesions of the female genital tract and are classified as lowrisk (LR) or high-risk (HR) based on their potential to cause cancer [5]. There are at least 18 HR-HPV types [6,7], of which HPV $16,18,31,33,35,45,52$, and 58 contribute to $91 \%$ of the invasive cervical cancers diagnosed and HPV 16 and 18 account for approximately $70 \%$ of all the case worldwide each year [8], while HPV 6, 11, 42, 43 and 44 are classified as "LR types", which are associated with hyperplastic lesions such as genital warts [5].

Since persistent infection of HPV is a necessary cause of cervical cancer worldwide, DNA tests for the detection of HPV can be used as a primary screening method 
for precancerous lesions and cervical cancer, and for triage of women with atypical or borderline cervical smears $[9,10]$. In addition, the data of HPV type-specific distribution will provide guidance for the vaccination program for cervical cancer. Prophylactic vaccines against HPV have been developed and approved in more than 100 countries around the world [11]. However, in China, HPV vaccines are still under clinical trials for government approval. There are two available HPV vaccines, a bivalent vaccine targeted at HPV 16 and 18 and a quadrivalent HPV vaccine targeted at HPV 6, 11, 16 and 18 [12,13]. These current preventive HPV vaccines offer protection only against a few HPV genotypes. HPV prevalence and subtype distribution varied greatly amongst different geographic areas $[14,15]$. Since limited cross-protection was present between HPV types [16], knowledge of geographical differences in HPV type-specific distribution might be very valuable for predicting the effect of current prophylactic vaccines and forming the basis for the second generation vaccines targeted to specific regions.

To the best of our knowledge, limited large scale epidemiologic data of HPV infection have been reported in Zhejiang Province, a coastal region in Southeast China. In this study, we collected 15,267 samples from women attending regular gynecological visits in Zhejiang Province. All women were offered HPV test and ThinPrep cytology test (TCT) to analyze the association between HPV genotype and cervical cytology. The overall, agespecific, genotype-specific, and state-specific prevalence of HPV in Zhejiang province will provide guidance for the future screening strategies of cervical cancer and vaccination program.

\section{Methods}

\section{Study population}

The study population consisted of 15,267 women (age, 1879 years; mean, $38.3 \pm 7.1$ years) attending a gynecological outpatient clinic between January 2010 to December 2013 in Zhejiang Province. A woman was considered eligible to enter the study if she a) had current or past sexual activity, b) was not pregnant at the time of enrollment, c) had never been screened or treated for cervical cancer, d) had not undergone a total uterus or cervix resection, e) agreed to undergo an HPV test and a TCT, and f) agreed to participate in the present study. This research was conducted in accordance with the Declaration of Helsinki and a protocol approved by the Ethics Committee of Zhejiang Medical College (Hangzhou, China).

\section{TCT and pathological diagnosis}

Exfoliated cervical cells were collected from the orifice of uterus and endocervical canal with a cervical brush. The cells were washed into vials containing ThinPrep preservative solution and were sent to the cytology laboratory for TCT analysis. Cytological findings were evaluated according to the Bethesda classification system [17] and were classified as follows: a) negative; b) atypical squamous cells of undetermined significance (ASCUS); c) low-grade squamous intraepithelial lesion (LSIL); d) atypical squamous cells that cannot exclude HSIL (ASC-H); e) high-grade squamous intraepithelial lesion (HSIL).

\section{HPV detection and genotyping}

HPV DNA was extracted from the cytological remnants, and was detected and genotyped using a commercial HPV Genotyping Kit for 23 HPV types (Yaneng Bioscience (Shenzhen) Co., Ltd, China), including 5 LR types $(6,11,42,43$ and 44$)$, and 18 HR types $(16,18$, $31,33,35,39,45,51,52,53,56,58,59,66,68,73,82$ and 83). The kit employs DNA amplification to detect HPV positivity and a microarray format with a nylon membrane onto which HPV genotype-specific oligonucleotide probes have been immobilized to simultaneously identify $23 \mathrm{HPV}$ genotypes. The HPV test was conducted according to the manufacturer's recommendation and was validated through the use of positive and negative controls at each shift.

\section{Statistical analysis}

The data were analyzed using SPSS software for windows (version 16.0). The prevalence of HPV according to age and cytological lesion types was analyzed. The $95 \%$ confidence intervals (CI) of HPV prevalence were based on normal approximations. Chi-square test was used to compare the proportions between different groups, with crude odds ratios (ORs) and 95\% CI calculation to estimate the risk of each HPV type for cervical lesions. Linear-by-linear association test was used to investigate trend in distribution of HPV infection according to grade of cytology abnormalities. $P$-values were two-sided, and statistical significance was defined as $\mathrm{p}<0.05$.

\section{Results}

\section{Overall HPV prevalence}

A total of 15,267 female out patients were enrolled in this study, of which 3,486 cases $(22.8 \%)$ were positive for HPV infection. The prevalence of single HR-HPV was $15.8 \%(2408 / 15267)$ and single LR-HPV was 3.1\% (474/ 15267). Multiple HPV infection was found in $4.0 \%$ (604/ 15267) of all the samples. Among women with multiple infections, 82.0\% (495/604) were infected with two HPV types, $12.4 \%(75 / 604)$ were with three types and 5.6\% (34/604) were with more than three types. Of the HPV positive cases, $69.1 \%(2408 / 3486)$ were single HR-HPV infections, $13.6 \%(474 / 3486)$ were single LR-HPV infections, and $17.3 \%(604 / 3486)$ were infected by multitypes, respectively. 


\section{HPV prevalence by age}

HPV prevalence by age group was examined in order to assess age trends in relation to HPV infection in more detail. Women were 18-79 years old (mean age 38.3) and were divided into six groups according to their age. As shown in Figure 1, the age-specific prevalence of total HPV infection exhibited a peak of 55.7\% (206/370, Pearson's Chi Square test, $\left.\mathrm{x}^{2}=276.3, \mathrm{p}<0.001\right)$ at $\leq 20$ years old and a second peak 35.5\% (54/152, Pearson's Chi Square test, $\left.\mathrm{x}^{2}=25.557, \mathrm{p}<0.001\right)$ at the age group $>$ 60 years old. Similarly, the prevalence of single HR-HPV and multiple HPV also exhibited the bimodal age distribution. However, single LR-HPV infection showed relatively flat curve.

\section{HPV prevalence by type}

Using the microarray method, totally $23 \mathrm{HPV}$ types were detected (18 HR types, 5 LR types). Overall, HPV 16 was the most commonly detected genotype present with a prevalence of $4.4 \%(678 / 15267)$, followed by HPV 58 (2.9\%, 444/15267), HPV 52 (2.7\%, 414/15267), HPV $33(2.2 \%, 331 / 15267)$ and HPV 11 (1.9\%, 294/15267) (Figure 2). Although HPV 11 is a LR type, its prevalence is higher than some other HR-HPVs, such as HPV 18 and HPV 31.

\section{HPV prevalence by cervical cytology}

As shown in Table 1, the overall HPV prevalence in normal, ASC-US, LSIL and HSIL cytology samples were 16.8\% (2330/13891), 80.2\% (644/828), 91.2\% (237/260) and $94.4 \%$ (102/108), respectively. As expected, HPV prevalence increased with the severity of the cytologic result (Pearson's Chi Square test, $\mathrm{p}<0.001$; Linear-byLinear association test, $\mathrm{p}<0.001)$. Moreover, multiple HPV positivity also exerted a similar increasing trend

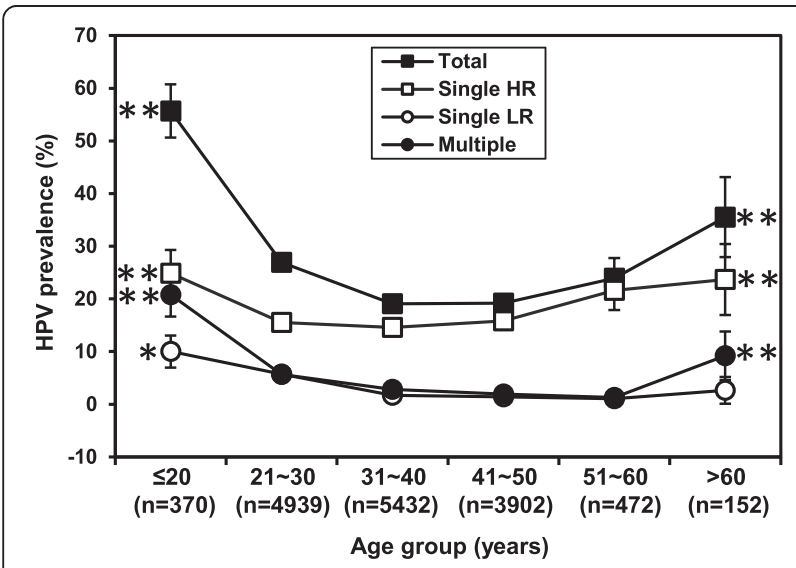

Figure 1 Age-specific prevalence of total HPV, single HR-HPV, single LR-HPV and multiple HPV with $95 \% \mathrm{Cl}$. Significant

differences between the peak and lowest prevalence are indicated as: ${ }^{*} \mathrm{p}<0.05 ;{ }^{* *} \mathrm{p}<0.01$ with the development of cytology abnormalities (Pearson's Chi Square test, $\mathrm{p}<0.001$; Linear-by-Linear association test, $\mathrm{p}<0.001)$.

In order to estimate the risk of HPV infection to have abnormal cytology, the crude ORs for the prevalence of HPV associated with abnormal cytology (ASC-US, LSIL, ASC-H and HSIL) are shown in Figure 3. The overall OR of HPV infection was 26.1 (95\% CI 22.4 to 30.3). As far as genotypes were concerned, HPV type 73 had the highest OR, followed by HPV 16, 82, 45, and 51. The LR-HPV type with $\mathrm{OR}>1$ was HPV 11 and 42. Additionally, the prevalence of HR-HPV 83, LR-HPV 6, 43 and 44 in the abnormal specimens showed no significant difference to that in the normal specimens (Pearson's Chi Square test, $\mathrm{p}>0.05)$ and no ORs were supplied.

\section{Discussion}

We presented a large clinic-based study (15,267 women) of HPV prevalence in the area of Zhejiang Province, Southeast China, from which interesting conclusions can be drawn. HPV detection and genotyping have been suggested to be incorporated in primary screening of cervical lesions $[18,19]$. HPV typing is also very important for characterization of the population in HPV vaccination trials and for monitoring the efficacy of HPV vaccines [13]. Accordingly, determination of type-specific HPV prevalence in a region is considered to be one of the important steps towards cervical cancer prevention.

It was observed that the overall HPV infection was $22.8 \%$ in female outpatients in this study. The overall HPV prevalence reported from different regions of China varied greatly, ranging from 7.2\% (Chaozhou, South China) to $36.5 \%$ (Harbin, Northeast China) [15,20]. HPV infection in our study population was similar to that in Fujian, Southeast China (22.5\%) [21], but higher than that in a previous population-based study in Zhejiang (13.3\%) [22]. The difference might primarily be attributed to the fact that our work was a clinic-based study with a much larger study cohort. In addition to geographical differences, the observed HPV prevalence was also affected by the study cohorts (clinic-based or populationbased), examination methods and time period [23].

We presented the age-related prevalence curves of HPV infections. The prevalence of total HPV, single HRHPV and multiple HPV, all showed bimodal age distribution, with a peak at the $\leq 20$ age group and a second one at the $>60$ age group. This has been observed in several other studies in China [1,14,24], but differs from most of the European countries, with a decrease in HPV prevalence after age 20 and a levelling off after age 45 $[25,26]$. The actual first peak may due to the fact that younger women are more prone to have multiple partners [27] and are also less likely to have developed immunity to HPV [28]. The second peak of HPV infection 


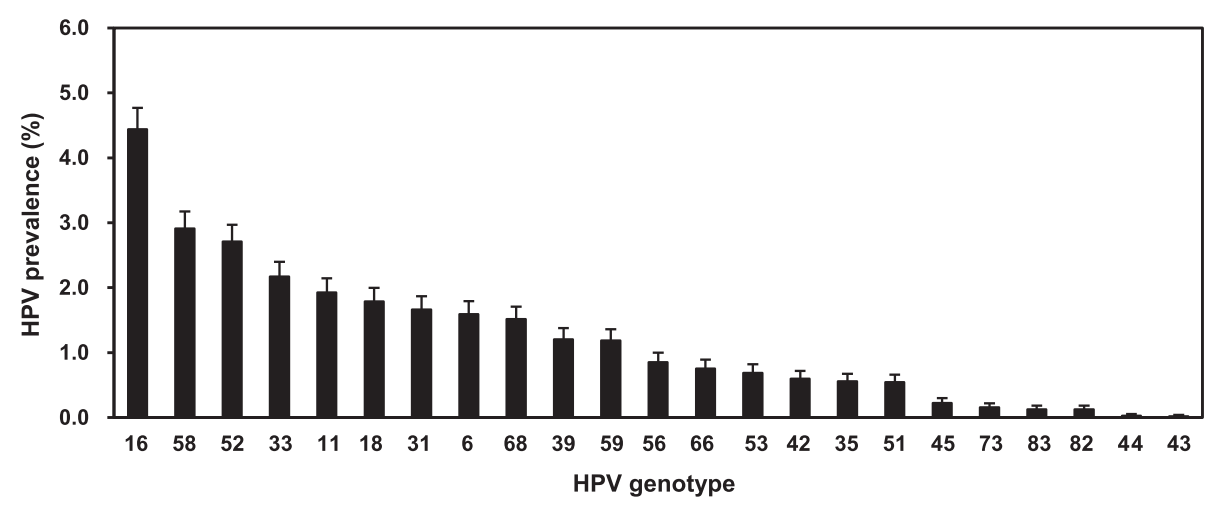

Figure 2 Overall prevalence of different HPV genotypes. There are 18 HR-HPVS $(16,18,31,33,35,39,45,51,52,53,56,58,59,66,68,73,82$ and 83) and 5 LR-HPVs $(6,11,42,43$, and 44).

Table 1 HPV type distribution by cytological results

\begin{tabular}{|c|c|c|c|c|c|}
\hline $\begin{array}{l}\text { HPV } \\
\text { type }\end{array}$ & $\begin{array}{l}\text { Normal (13891) } \\
\text { N (\%) }\end{array}$ & $\begin{array}{l}\text { ASC-US (828) } \\
\text { N (\%) }\end{array}$ & $\begin{array}{l}\text { LSIL (260) } \\
\text { N (\%) }\end{array}$ & $\begin{array}{l}\text { ASC-H (180) } \\
\text { N (\%) }\end{array}$ & $\begin{array}{l}\text { HSIL (108) } \\
\text { N (\%) }\end{array}$ \\
\hline \multicolumn{6}{|l|}{ HR-HPV } \\
\hline 16 & 345 (2.5) & $180(21.7)$ & 65 (25.0) & 65 (36.1) & $23(21.3)$ \\
\hline 18 & 154 (1.1) & 89 (10.7) & $18(6.9)$ & $9(5.0)$ & $3(2.8)$ \\
\hline 31 & $141(1.0)$ & $75(9.1)$ & $22(8.5)$ & $5(2.8)$ & $11(10.2)$ \\
\hline 33 & 190 (1.4) & $63(7.6)$ & $26(10.0)$ & 25 (13.9) & $27(25.0)$ \\
\hline 35 & $67(0.5)$ & $12(1.4)$ & $4(1.5)$ & $2(1.1)$ & $0(0.0)$ \\
\hline 39 & 140 (1.0) & $34(4.1)$ & $5(1.9)$ & $4(2.2)$ & $1(0.9)$ \\
\hline 45 & $17(0.1)$ & $11(1.3)$ & $2(0.8)$ & $2(1.1)$ & $2(1.9)$ \\
\hline 51 & $42(0.3)$ & $19(2.3)$ & $13(5.0)$ & $4(2.2)$ & $5(4.6)$ \\
\hline 52 & 270 (1.9) & 90 (10.9) & 38 (14.6) & $12(6.7)$ & $4(3.7)$ \\
\hline 53 & $87(0.6)$ & $10(1.2)$ & $5(1.9)$ & $3(1.7)$ & $0(0.0)$ \\
\hline 56 & $92(0.7)$ & $9(1.1)$ & $22(8.5)$ & $5(2.8)$ & $2(1.9)$ \\
\hline 58 & $264(1.9)$ & $93(11.2)$ & $32(12.3)$ & $12(6.7)$ & 43 (39.8) \\
\hline 59 & 154 (1.1) & $21(2.5)$ & $1(0.4)$ & $3(1.7)$ & $2(1.9)$ \\
\hline 66 & $70(0.5)$ & $29(3.5)$ & $9(3.5)$ & $6(3.3)$ & $1(0.9)$ \\
\hline 68 & $186(1.3)$ & $17(2.1)$ & $17(6.5)$ & 7 (3.9) & $4(3.7)$ \\
\hline 73 & $8(0.1)$ & $4(0.5)$ & $7(2.7)$ & $4(2.2)$ & $1(0.9)$ \\
\hline 82 & $9(0.1)$ & $3(0.4)$ & $3(1.2)$ & $4(2.2)$ & $0(0.0)$ \\
\hline 83 & $15(0.1)$ & $3(0.4)$ & $0(0.0)$ & $1(0.6)$ & $0(0.0)$ \\
\hline \multicolumn{6}{|l|}{ LR-HPV } \\
\hline 6 & 221 (1.6) & $15(1.8)$ & $4(1.5)$ & $2(1.1)$ & $1(0.9)$ \\
\hline 11 & 257 (1.9) & $24(2.9)$ & $8(3.1)$ & $5(2.8)$ & $0(0.0)$ \\
\hline 42 & $73(0.5)$ & $13(1.6)$ & $3(1.2)$ & $2(1.1)$ & $0(0.0)$ \\
\hline 43 & $2(0.0)$ & $1(0.1)$ & $0(0.0)$ & $0(0.0)$ & $0(0.0)$ \\
\hline 44 & $3(0.0)$ & $0(0.0)$ & $1(0.4)$ & $0(0.0)$ & $0(0.0)$ \\
\hline Any type & $2330(16.8)$ & $664(80.2)$ & $237(91.2)$ & $153(85.0)$ & $102(94.4)$ \\
\hline Single & $1921(13.8)$ & $551(66.5)$ & $194(74.6)$ & 133 (73.9) & 83 (76.9) \\
\hline Multiple & 409 (2.9) & 113 (13.6) & $43(16.5)$ & $20(11.1)$ & 19 (17.6) \\
\hline Negative & 11561 (83.2) & 164 (19.8) & $23(8.8)$ & 27 (15.0) & $6(5.6)$ \\
\hline
\end{tabular}




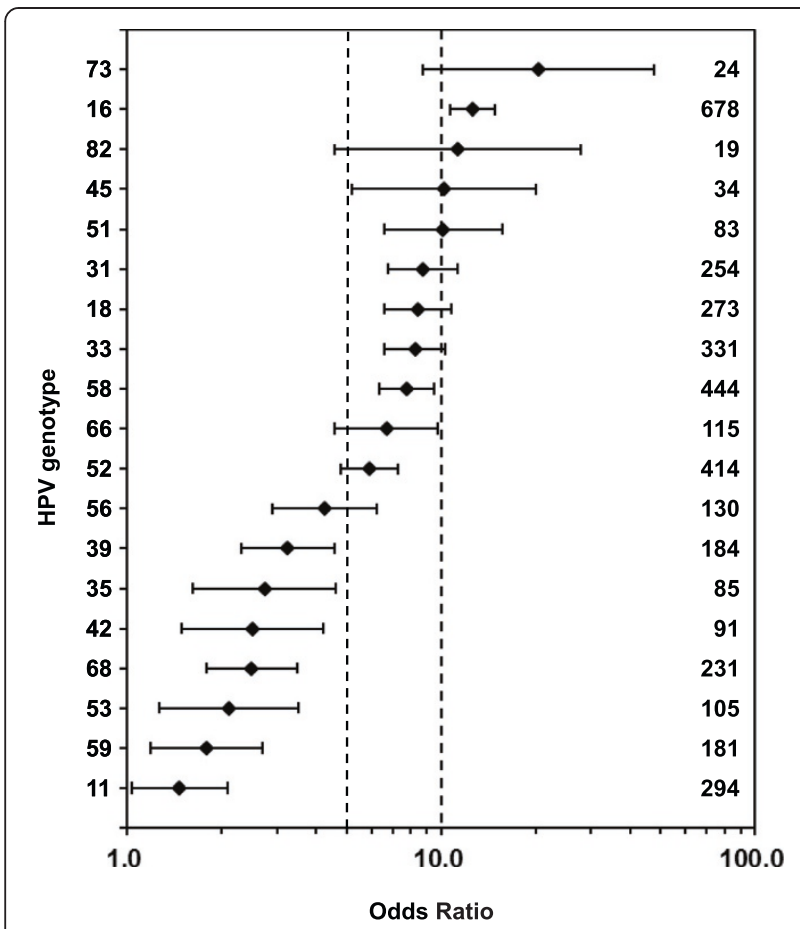

Figure 3 Risk of each HPV type for cervical lesions. Crude odds ratios with 95\% confidence intervals for the prevalence of HPV associated with abnormal cytology (ASC-US, LSIL, ASC-H and HSIL) are provided. Numbers on right margin are the total number of positive specimens infected by the specified type. The prevalence of HR-HPV 83, LR-HPV 6, 43 and 44 in abnormal specimens showed no significant difference to normal specimens (Pearson's Chi Square test, $p>0.05$ ) and no ORs were provided. Reference lines for ORs of 5 and 10 are added for readability.

in women aged $>60$ years should also arouse enough attention. The high infection rate around menopausal women may be attributed to viral persistence or reactivation of latent HPV caused by the physiologic and immunologic dysregulation at menopausal transition [29,30]. Accordingly, HPV detection is clinically valuable for perimenopausal women in cervical cancer screening program. However, since HPV prophylactic vaccines do not have clinical benefit in women infected with vaccine types at the time of vaccination, we assume that younger women would obtain more benefit from "catch-up" HPV vaccination programs.

The five most common HPV types in women with normal cytology worldwide are HPV 16, 18, 31, 58 and 52 , while the rank varied by region [31]. HPV 16 and HPV 18 are the most common oncogenic types associated with cancer, and are targeted by the vaccines $[8,12]$. In our population, the five most common HPV types were HPV 16, 58, 52, 33 and 11 basing on the overall prevalence. Similarly to most previous surveys in China $[15,24]$ and other population [7,32], HPV 16 was the most common type. Somewhat differently, HPV 58 and 52 were more prevalent than the vaccine type HPV 18 in our population. Moreover, no matter in normal, ASCUS, LSIL, ASC-H or HSIL cytology samples, HPV 16, 58 and 52 were always the major type, with the rank varied. Especially, HPV 58 was the most prevalent type in HSIL cytology samples. Some previous studies have shown that HPV 58 and 52 were more prevalent and overrepresented in cervical cancer cases in Asia [33,34]. In China, it was observed that the two HPV types were more prevalent in the south and the southwest compared to other regions among women with precancerous lesions and cervical cancer [35-37]. The preponderance of HPV 58 and 52 in our study population is meaningful, which enhances the hypothesis that the second-generation HPV prophylactic vaccines including HPV 58 and 52 may offer higher protection for women in China and other Asian areas.

As far as cytology were concerned, it was observed that the overall HPV prevalence in normal, ASC-US, LSIL and HSIL cytology samples were $16.8 \%, 80.2 \%, 91.2 \%$ and 94.4\%, respectively. Overall HPV prevalence increased as lesions progressed to higher grade ones, suggesting that HPV infection carries an increased risk of developing cervical neoplasia. The same trend was also observed in other regions or countries. For examples, in Henan, Central China, the overall HPV prevalence in normal, ASC-US, LSIL and HSIL cytology samples were 57.1\%, 72.5\%, 84.0\% and $88.6 \%$, respectively [38]. A population-based study of HPV genotype prevalence in America showed that the overall HPV infections were found in 24.3\%, 57.9\%, 94.6\% and $95.5 \%$ of normal, ASC-US, LSIL and HSIL cytology samples, respectively [13]. The risk of each HPV type for cervical lesions was estimated using crude ORs. The overall OR of HPV infection was 26.1 (95\% CI 22.4 to 30.3), showing that the cervical lesion risk of HPV-infected women increases to about 26-fold of those uninfected women. The five most risky HPV types were 73, 16, 82, 45 and 51 . HPV 73 had the highest OR for abnormal cytology (ASC-US, LSIL, ASC-H and HSIL). Although the overall prevalence of HPV 73 was relatively low (0.2\%), HPV 73 infection was at the highest risk of abnormality, which should be taken more attention to. The association of HPV 73 and HPV82 with cervical epithelial lesions were confirmed and the two types were classified as HR type in previous studies [6,39]. HPV 73 was even more risky than HPV 16 based on HPV-type-specific risk analysis in Bahia, Brazil [40] and Northwest Germany [41], which was consistent with our results in this study.

\section{Conclusion}

We presented a large cross-sectional study, from which baseline data of HPV prevalence in Zhejiang Province was provided. HPV prevalence showed bimodal age distribution, with a peak at the $\leq 20$ age group and a second one at $>60$ age group. HPV 16, 58 and 52 were the most 
commonly identified HR-HPV types while the vaccine type HPV 18 showed relatively low prevalence. As expected, HPV prevalence increased as lesions progressed to higher grade ones. HPV $73,16,82,45$, and 51 were the most risky types in this area. Our data will provide guidance for the primary screening and vaccination program for cervical cancer.

\section{Abbreviations}

HPV: Human papillomavirus; LR: Low-risk; HR: High-risk; ASC: Atypical squamous cell; ASC-US: Atypical squamous cells of undetermined significance; ASC-H: Atypical squamous cells that cannot exclude HSIL; SIL: Squamous intraepithelial lesion; LSIL: Low-grade SIL; HSIL: High-grade SIL; ORs: Odds ratios; Cl: Confidence interval; TCT: ThinPrep cytology test.

\section{Competing interests}

The authors declare that they have no competing interests.

\section{Authors' contributions}

$\mathrm{XXL}$ and $\mathrm{XLF}$ contributed equally to this work, they collected the samples and carried out the molecular tests, participated in the statistical analysis and drafted the manuscript. YPY performed gynaecologic examinations, participated in sample collection, and helped to draft the manuscript. LJ participated in the molecular tests and the statistical analysis. AHS designed and coordinated the study and helped to draft the manuscript. JY participated in the design of the study and helped to draft the manuscript. All authors read and approved the final manuscript.

\section{Acknowledgements}

This work was supported by Grants from the National Natural Sciences Foundation of China (81271893), the Natural Science Foundation of Zhejiang Province (LY12H19002) and Zhejiang Provincial Program for the Cultivation of High-level Innovative Health Talents.

We would like to thank Leyang Yuan (PhD, Zhejiang Museum of Natural History) for his assistance with statistical analysis and Peng Du (MD, Zhejiang Medical College) for his assistance with sample collection. We also gratefully acknowledge thousands of women who have participated in this study.

\section{Author details}

${ }^{1}$ Faculty of Basic Medicine, Zhejiang Medical College, Zhejiang, Hangzhou 310053, P. R. China. ${ }^{2}$ Division of Basic Medical Microbiology, State Key Laboratory for Diagnosis and Treatment of Infectious Diseases, First Affiliated Hospital of Zhejiang University, Hangzhou, Zhejiang 310003, P. R. China. ${ }^{3}$ Department of Medical Microbiology and Parasitology, College of Medicine, Zhejiang University, Hangzhou, Zhejiang 310058, P. R. China.

Received: 21 August 2014 Accepted: 11 December 2014 Published: 19 December 2014

\section{References}

1. Zhao FH, Lewkowitz AK, Hu SY, Chen F, Li LY, Zhang QM, Wu RF, Li CQ, Wei LH, $X U A D$, Zhang WH: Prevalence of human papillomavirus and cervical intraepithelial neoplasia in China: a pooled analysis of 17 population-based studies. Int J Cancer 2012, 131(12):2929-2938.

2. Ferlay J, Shin HR, Bray F, Forman D, Mathers C, Parkin DM: Estimates of worldwide burden of cancer in 2008: GLOBOCAN 2008. Int J Cancer 2010, 127(12):2893-2917.

3. Hu SY, Hong Y, Zhao FH, Lewkowitz AK, Chen F, Zhang WH, Pan QJ, Zhang X, Fei C, Li H, Qiao YL: Prevalence of HPV infection and cervical intraepithelial neoplasia and attitudes towards HPV vaccination among Chinese women aged 18-25 in Jiangsu province. Chin J Cancer Res 2011, 23(1):25-32.

4. Walboomers JM, Jacobs MV, Manos MM, Bosch FX, Kummer JA, Shah KV, Snijders PJ, Peto J, Meijer CJ, Muñoz N: Human papillomavirus is a necessary cause of invasive cervical cancer worldwide. J Pathol 1999, 189(1):12-19.

5. Baseman JG, Koutsky LA: The epidemiology of human papillomavirus infections. J Clin Virol 2005, 32(Suppl 1):S16-24.
6. Muñoz N, Bosch FX, de Sanjose S, Herrero R, Castellsagué X, Shah KV, Snijders PJ, Meijer CJ, International Agency for Research on Cancer Multicenter Cervical Cancer Study Group: Epidemiologic classification of human papillomavirus types associated with cervical cancer. N Engl J Med 2003, 348(6):518-527.

7. Argyri E, Papaspyridakos S, Tsimplaki E, Michala L, Myriokefalitaki E, Papassideri I, Daskalopoulou D, Tsiaoussi I, Magiakos G, Panotopoulou E: A cross sectional study of HPV type prevalence according to age and cytology. BMC Infect Dis 2013, 13:53.

8. de Sanjose S, Quint WGV, Alemany L, Retrospective International Survey and HPV Time Trends Study Group: Human papillomavirus genotype attribution in invasive cervical cancer: a retrospective cross-sectional worldwide study. Lancet Oncol 2010, 11(11):1048-1056.

9. Boulet GA, Horvath CA, Berghmans S, Bogers J: Human papillomavirus in cervical cancer screening: important role as biomarker. Cancer Epidemiol Biomarkers Prev 2008, 17(4):810-817

10. 10. Catteau X, Simon P, Noël JC: Evaluation of the Oncogenic Human Papillomavirus DNA Test with Liquid-Based Cytology in Primary Cervical Cancer Screening and the Importance of the ASC/SIL Ratio: A Belgian Study. ISRN Obstet Gynecol 2014, 2014:536495.

11. Liu X, Feng A, Cui Y, Tobe RG: Prevention of human papillomavirus (HPV) infection and cervical cancer in China: how does HPV vaccination bring about benefits to Chinese women? Biosci Trends 2013, 7(4):159-167.

12. Banura C, Mirembe FM, Katahoire AR, Namujju PB, Mbonye AK, Wabwire FM: Epidemiology of HPV genotypes in Uganda and the role of the current preventive vaccines: A systematic review. Infect Agent Cancer 2011, 6(1):11.

13. Wheeler CM, Hunt WC, Cuzick J, Langsfeld E, Pearse A, Montoya GD, Robertson M, Shearman CA, Castle PE, New Mexico HPV Pap Registry Steering Committee: A population-based study of human papillomavirus genotype prevalence in the United States: baseline measures prior to mass human papillomavirus vaccination. Int J Cancer 2013, 132(1):198-207.

14. Liu SS, Chan KY, Leung RC, Chan KK, Tam KF, Luk MH, Lo SS, Fong DY, Cheung AN, Lin ZQ, Ngan HY: Prevalence and risk factors of Human Papillomavirus (HPV) infection in southern Chinese women - a population-based study. PLoS One 2011, 6(5):e19244.

15. Li J, Huang R, Schmidt JE, Qiao YL: Epidemiological features of Human Papillomavirus (HPV) infection among women living in Mainland China. Asian Pac J Cancer Prev 2013, 14(7):4015-4023.

16. Herrero R: Human papillomavirus (HPV) vaccines: limited cross-protection against additional HPV types. J Infect Dis 2009, 199(7):919-922.

17. Solomon D, Davey D, Kurman R, Moriarty A, O'Connor D, Prey M, Raab S, Sherman M, Wilbur D, Wright T Jr, Young N, Forum Group Members: The 2001 Bethesda System: terminology for reporting results of cervical cytology. JAMA 2002, 287:2114-2119.

18. Villa L, Denny L: Methods for detection of HPV infection and its clinical utility. Int J Gynecol Obstet 2006, 94(Suppl 1):S71-80.

19. Zorzi M, Del Mistro A, Farruggio A, de'Bartolomeis L, Frayle-Salamanca H, Baboci L, Bertazzo A, Cocco P, Fedato C, Gennaro M, Marchi N, Penon MG, Cogo C, Ferro A: Use of a high-risk human papillomavirus DNA test as the primary test in a cervical cancer screening programme: a population-based cohort study. BJOG 2013, 120(10):1260-1267.

20. Sun B, He J, Chen X, He M, He Z, Wang Y, Shang Q, Yu L, Wei L: Prevalence and genotype distribution of human papillomavirus infection in Harbin, Northeast China. Arch Virol 2014, 159(5):1027-1032.

21. Wu D, Cai L, Huang M, Zheng Y, Yu J: Prevalence of genital human papillomavirus infection and genotypes among women from Fujian province, PR China. Eur J Obstet Gynecol Reprod Biol 2010, 151(1):86-90.

22. Ye J, Cheng $X$, Chen $X, Y e F, L u ̈ W, X i e X$ : Prevalence and risk profile of cervical Human papillomavirus infection in Zhejiang Province, southeast China: a population-based study. Virol J 2010, 7:66.

23. Uusküla A, Kals M, Kosenkranius L, McNutt LA, DeHovitz JJ: Populationbased type-specific prevalence of high-risk human papillomavirus infection in Estonia. BMC Infect Dis 2010, 10:63.

24. Sun $L L$, Jin $Q$, Li H, Zhou XR, Song ZQ, Cheng XM, Tao T, Liang $B$, Xu L, Wang YR, Zhen Y, He JW, Shen K: Population-based study on the prevalence of and risk factors for human papillomavirus infection in Qujing of Yunnan province, Southwest China. Virol J 2012, 9:153.

25. Kjaer SK, Breugelmans G, Munk C, Junge J, Watson M, Iftner T: Populationbased prevalence, type- and age-specific distribution of HPV in women before introduction of an HPV-vaccination program in Denmark. Int J Cancer 2008, 123(8):1864-1870. 
26. Bonde J, Rebolj M, Ejegod DM, Preisler S, Lynge E, Rygaard C: HPV prevalence and genotype distribution in a population-based split-sample study of well-screened women using CLART HPV2 Human Papillomavirus genotype microarray system. BMC Infect Dis 2014, 14(1):413.

27. Zhao FH, Tiggelaar SM, Hu SY, Xu LN, Hong Y, Niyazi M, Gao XH, Ju LR, Zhang LQ, Feng XX, Duan XZ, Song XL, Wang J, Yang Y, Li CQ, Liu JH, Liu JH, Lu YB, Li L, Zhou Q, Liu JF, Zhao N, Schmidt JE, Qiao YL: A multi-center survey of age of sexual debut and sexual behavior in Chinese women: suggestions for optimal age of human papillomavirus vaccination in China. Cancer Epidemiol 2012, 36(4):384-390.

28. Winer RL, Feng Q, Hughes JP, O'Reilly S, Kiviat NB, Koutsky LA: Risk of female human papillomavirus acquisition associated with first male sex partner. J Infect Dis 2008, 197(2):279-282.

29. Althoff KN, Paul P, Burke AE, Viscidi R, Sangaramoorthy M, Gravitt PE: Correlates of cervicovaginal human papillomavirus detection in perimenopausal women. J Womens Health (Larchmt) 2009, 18(9):1341-1346.

30. Kang LN, Castle PE, Zhao FH, Jeronimo J, Chen F, Bansil P, Li J, Chen W, Zhang X, Qiao YL: A prospective study of age trends of high-risk human papillomavirus infection in rural China. BMC Infect Dis. 2014, 14:96.

31. de Sanjose S, Diaz M, Castellsague X, Clifford G, Bruni L, Munoz N, Bosch FX: Worldwide prevalence and genotype distribution of cervical human papillomavirus DNA in women with normal cytology: a meta-analysis. Lancet Infect Dis 2007, 7(7):453-459.

32. Jiang Y, Brassard P, Severini A, Mao Y, Li YA, Laroche J, Chatwood S, Corriveau A, Kandola K, Hanley B, Sobol I, Ar-Rushdi M, Johnson G, Lo J, Ratnam S, Wong T, Demers A, Jayaraman G, Totten S, Morrison H: The prevalence of human papillomavirus and its impact on cervical dysplasia in Northern Canada. Infect Agent Cancer 2013, 8(1):25.

33. Bao YP, Li N, Smith JS, Qiao YL: Human papillomavirus type distribution in women from Asia: a meta-analysis. Int J Gynecol Cancer 2008, 18(1):71-79.

34. Kim MJ, Kim JJ, Kim S: Type-specific prevalence of high-risk human papillomavirus by cervical cytology and age: Data from the health check-ups of 7,014 Korean women. Obstet Gynecol Sci 2013, 56(2):110-120.

35. Chen W, Zhang X, Molijn A, Jenkins D, Shi JF, Quint W, Schmidt JE, Wang P, Liu YL, Li LK, Shi H, Liu JH, Xie X, Niyazi M, Yang P, Wei LH, Li LY, Li J, Liu JF, Zhou Q, Hong Y, Li L, Li Q, Zhou HL, Bian ML, Chen J, Qiao YL, Smith JS: Human papillomavirus type-distribution in cervical cancer in China: the importance of HPV 16 and 18. Cancer Causes Control 2009, 20(9):1705-1713.

36. Chen $Q$, Xie LX, Qing ZR, Li LJ, Luo ZY, Lin M, Zhang SM: Epidemiologic characterization of human papillomavirus infection in rural Chaozhou Eastern Guangdong Province of China. PLoS One 2012, 7:e32149.

37. Li J, Mei J, Wang $X$, Hu L, Lin Y, Yang P: Human papillomavirus type-specific prevalence in women with cervical intraepithelial neoplasm in Western China. J Clin Microbiol 2012, 50(3):1079-1081.

38. Shen Y, Gong JM, Li YQ, Gong YM, Lei DM, Cheng GM, Li XF: Epidemiology and genotype distribution of human papillomavirus (HPV) in women of Henan Province, China. Clin Chim Acta 2013, 415:297-301.

39. Meyer T, Arndt R, Beckmann ER, Padberg B, Christophers E, Stockfleth E: Distribution of HPV 53, HPV 73 and CP8304 in genital epithelial lesions with different grades of dysplasia. Int I Gynecol Cancer 2001, 11(3):198-204.

40. Bruno A, Serravalle K, Travassos AG, Lima BG: Genotype distribution of human papillomavirus in women from the state of Bahia, Brazil. Rev Bras Ginecol Obstet 2014, 36(9):416-422.

41. de Jonge M, Busecke G, Heinecke A, Bettendorf O: Human papillomavirus genotype distribution in cytologically screened women from northwest Germany. Acta Cytol 2013, 57(6):591-598.

doi:10.1186/s12879-014-0708-8

Cite this article as: Liu et al:: Human papillomavirus prevalence and type-distribution among women in Zhejiang Province, Southeast China: a cross-sectional study. BMC Infectious Diseases 2014 14:708.

\section{Submit your next manuscript to BioMed Central and take full advantage of:}

- Convenient online submission

- Thorough peer review

- No space constraints or color figure charges

- Immediate publication on acceptance

- Inclusion in PubMed, CAS, Scopus and Google Scholar

- Research which is freely available for redistribution

Submit your manuscript at www.biomedcentral.com/submit
() Biomed Central 